\title{
Impact of treatment intensity on infectious complications in patients with acute myeloid leukemia
}

Sebastian Scholl ( $\sim$ sebastian.scholl@med.uni-jena.de )

Jena University Hospital: Universitatsklinikum Jena https://orcid.org/0000-0003-2893-3630

Romy Tober

Jena University Hospital: Universitatsklinikum Jena

Ulf Schnetzke

Jena University Hospital: Universitatsklinikum Jena

Maximilian Fleischmann

Jena University Hospital: Universitatsklinikum Jena

Olaposi Yomade

Jena University Hospital: Universitatsklinikum Jena

Karin G Schrenk

Jena University Hospital: Universitatsklinikum Jena

Jakob F Hammersen

Jena University Hospital: Universitatsklinikum Jena

Anita Glaser

Jena University Hospital: Universitatsklinikum Jena

Christian Thiede

Dresden University Hospital: Universitatsklinikum Carl Gustav Carus

Andreas Hochhaus

Jena University Hospital: Universitatsklinikum Jena

\section{Research Article}

Keywords: AML, infections, epigenetic therapy, induction chemotherapy, IFD, pneumonia

Posted Date: February 24th, 2022

DOI: https://doi.org/10.21203/rs.3.rs-1378367/v1

License: (c) (1) This work is licensed under a Creative Commons Attribution 4.0 International License.

Read Full License 
Working Title

\section{Impact of treatment intensity on infectious complications in patients with acute myeloid leukemia}

Romy Tober ${ }^{1}$, Ulf Schnetzke ${ }^{1}$, Maximilian Fleischmann ${ }^{1}$, Olaposi Yomade ${ }^{1}$, Karin Schrenk ${ }^{1}$, Jakob Hammersen ${ }^{1}$, Anita Glaser ${ }^{2}$, Christian Thiede ${ }^{3}$, Andreas Hochhaus ${ }^{1}$, Sebastian Scholl ${ }^{1 \#}$

${ }^{1}$ Klinik für Innere Medizin II, Abteilung Hämatologie und Internistische Onkologie, Universitätsklinikum Jena, Am Klinikum 1, 07747, Jena, Germany

${ }^{2}$ Institut für Humangenetik, Universitätsklinikum Jena, Am Klinikum 1, 07747, Jena, Germany

${ }^{3}$ Universitätsklinikum Carl Gustav Carus an der Technischen Universität Dresden, Dresden, Germany

${ }^{\#}$ Correspondence: Sebastian Scholl, MD

Klinik für Innere Medizin II

Abt. Hämatologie und Internistische Onkologie

Am Klinikum 1

07747 Jena

Germany

sebastian.scholl@med.uni-jena.de

Tel.: +49-3641-9324201

Fax.: +49-3641-9324202

Key words: AML, infections, epigenetic therapy, induction chemotherapy, IFD, pneumonia

Word count:

Abstract 488

Text 5189

Tables

6

Figures 2

Supplement: $\quad 3$ Tables, 3 Figures 


\section{Abstract}

Background: Infectious complications reflect a major challenge in the treatment of patients with acute myeloid leukemia (AML). Both induction chemotherapy and epigenetic treatment with hypomethylating agents (HMA) are associated with severe infections while neutropenia represents a common risk factor. Here, 220 consecutive and newly diagnosed AML patients were analyzed with respect to infectious complications dependent on treatment intensity and antifungal prophylaxis applied to these patients.

Patients and Methods: We retrospectively analyzed 220 patients with newly diagnosed AML at a tertiary care hospital between August 2016 and December 2020. The median age of AML patients undergoing induction chemotherapy ( $n=102)$ was 61 years (25-76 years). Patients receiving palliative AML treatment ( $n=118$ ) had a median age of 75 years (53-91 years). We assessed the occurrence of infectious complication including the classification of pulmonary invasive fungal disease (IFD) according to the EORTC/MSG criteria at diagnosis and until day 100 after initiation of AML treatment. Furthermore, admission to intensive care unit (ICU) and subsequent outcome was analyzed for both groups of AML patients, respectively.

Results: AML patients subsequently allocated to palliative AML treatment have a significantly higher risk of pneumonia at diagnosis compared to patients undergoing induction chemotherapy $(37.3 \% \mathrm{vs}$. $13.7 \%, P<0.001)$ including a higher probability of atypical pneumonia $(22.0 \%$ vs. $10.8 \%, P=0.026)$. Furthermore, urinary tract infections are more frequent in the palliative subgroup at the time of $A M L$ diagnosis $(5.1 \%$ vs. $0 \%, P=0.021)$. Surprisingly, the incidence of pulmonary IFD is significantly lower after initiation of palliative AML treatment compared to the occurrence after induction chemotherapy $(8.4 \%$ vs. $33.3 \%, P<0.001)$ despite only few patients of the palliative treatment group received Aspergillus spp.-directed antifungal prophylaxis. The overall risk for infectious complications at AML diagnosis is significantly higher for palliative AML patients at diagnosis while patients undergoing induction chemotherapy have a significantly higher risk of infections after initiation of AML treatment. In addition, there is a strong correlation between the occurrence of pneumonia including atypical pneumonia and pulmonary IFD and the ECOG performance status at diagnosis in the palliative AML patient group. Analysis of intensive care unit (ICU) treatment (e.g. in case of sepsis or pneumonia) for both subgroups reveals a positive outcome in 10 of 15 patients (66.7\%) with palliative AML treatment and in 15 of 18 patients (83.3\%) receiving induction chemotherapy. Importantly, the presence of infections and the ECOG performance status at diagnosis significantly correlate with the overall survival (OS) of palliative AML patients ( 315 days w/o infection vs. 69 days with infection, $P 0.0049$ and 353 days for $E C O G \leq 1$ vs. 50 days for $E C O G \geq 2, P<0.001$, respectively) in this intent-to-treat analysis.

Conclusion: The risk and the pattern of infectious complications at diagnosis and after initiation of AML therapy depends on age, ECOG performance status and subsequent treatment intensity. A comprehensive diagnostic work-up for identification of pulmonary IFD is indispensable for effective treatment of pneumonia in AML patients. The presence of infectious complications at diagnosis contributes to an inferior outcome in elderly AML patients. 


\section{Introduction}

Infectious complications play a pivotal role in patients with acute myeloid leukemia (AML) and contribute to morbidity and mortality of AML patients significantly. There is a broad spectrum of infectious complications ranging from blood stream infections (BSI) potentially associated with severe sepsis to fungal infections regularly presenting as pneumonia. Treatment-related mortality (TRM) following induction chemotherapy with cytarabine in combination with daunorubicin occurs in about $5 \%$ of AML patients while the major cause of fatal outcome is associated with BSI.[1,2] It remains difficult to estimate the pre-treatment risk of TRM which makes clinical evaluation especially in elderly AML patients even more important.[3] The rate of distinct complications (e.g., admission to intensive care unit, mechanic ventilation or dialysis) in AML patients undergoing intensive chemotherapy has been extensively reviewed in a large cohort of AML patients considering both baseline characteristics and dynamic parameters during AML treatment.[4]

BSI can regularly be detected in AML patients presenting with neutropenic fever and severe sepsis is associated with higher mortality in neutropenic patients.[5,6] BSI differs between patients with hematological diseases compared to those patients with solid tumors. [7,8] Multi-resistance of gramnegative bacteria has been demonstrated to be a key factor for increased mortality and prolonged hospitalization. [9] Colonization with carbapenem-resistant Enterobacteriaceae results in a significant increase of early death in AML patients undergoing induction chemotherapy.[10]

Pneumonia can be diagnosed in more than $25 \%$ of $A M L$ patients during induction chemotherapy.[11,12] While pulmonary infiltrates should be detected by low-dose computed tomography, recommended diagnostic work-up does also includes bronchoalveolar lavage (BAL) to specify the pathogens of opportunistic infections.[13,14]

Invasive fungal diseases (IFD) is classified according to the EORTC/MSG recommendations and have a high impact on morbidity and prognosis in AML patients undergoing intensive chemotherapy.[15,16] The risk of pulmonary IFD in AML patients is associated with severity and duration of neutropenia while such important clinical factors as age, renal or hepatic dysfunction affect the risk of death in AML patients who develop IFD.[17,18] In a large prospective multi-center registry, multivariate analysis revealed the impact of performance status, body weight and chronic obstructive pulmonary disease on the occurrence of IFD in AML patients.[19] Genetic factors of innate immune system might contribute to the susceptibility of infectious complications including pulmonary IFD in AML patients undergoing induction chemotherapy.[20,21] Antifungal prophylaxis with posaconazole has been established in AML induction chemotherapy and in patients with acute graft-versus-host disease following allogeneic stem cell transplantation (ASCT) improving overall survival..[22,23]

While several factors contributing to the risk of severe infectious complications in AML patients have been identified, the severity of neutropenia (i.e., absolute neutrophils count below 500/ $\mu \mathrm{L}$ ) at diagnosis is significantly associated with duration of neutropenia, bloodstream infections and subsequently early death following induction chemotherapy of AML.[24] Furthermore, unresolved neutropenia represents a risk factor to develop IFD in neutropenic patients while early lymphopenia results in a higher risk of febrile neutropenia.[25,26] In AML patients undergoing intensive induction chemotherapy, long-term neutropenia is regularly associated with treatment-related toxicity (e.g., mucositis) contributing to a pronounced risk for bloodstream infections. [27]

Conversely, elderly AML patients receiving palliative AML therapy based on epigenetic treatment approaches show less therapy-associated toxicity but they regularly present with IFD due to low absolute neutrophil counts (e.g. due to an antecedent myelodysplastic syndrome, MDS).[28] In addition, functional impairment of neutrophils in those patients with previous MDS contributes to the enhanced susceptibility towards severe infections in elderly AML patients.[29,30] 
Infection-related mortality can not only be observed in AML patients undergoing intensive induction chemotherapy but is also demonstrated in elderly AML patients receiving epigenetic treatment. So far, only few data exist on infectious complications of AML patients undergoing palliative treatment. [31,32] Recently, Jalbut and colleagues analyzed early infectious complications in AML patients either undergoing induction chemotherapy or treatment with hypomethylating agents.[33]

Based on a retrospective single-center analysis of 220 consecutive newly diagnosed AML patients, we sought to investigate the impact of potential risk factors (e.g., treatment regimen, antifungal prophylaxis) on the frequency and severity of infectious complications. 


\section{Patients and methods}

\section{Patient cohort and informed consent}

A total of 220 consecutive AML patients were identified at the Department of Hematology and Oncology, University Hospital Jena, Germany. Diagnosis and start of induction chemotherapy, epigenetic treatment or cytoreductive chemotherapy were between August 2016 and December 2020. The patient cohort considered all patients with newly diagnosed AML during this period including those AML patients treated with cytoreductive chemotherapy combined with best supportive care. Patients' characteristics are indicated in Table 1 and summarized in the CONSORT diagrams (Figure S1 and S2).

Performance status and co-morbidity index have been documented according to the criteria published by the Eastern Cooperative Oncology Group (ECOG) and by application of a modified version of the Charlson co-morbidity index, respectively.[34,35]

All patients were included in the SAL registry (Study Alliance Leukemia). Patients gave their written informed consent for data acquisition after pseudonymization and analysis in the SAL registry. The participation in the AML registry of the SAL study group and the retrospective analysis presented here have been approved separately by the Ethical review committee of the University Hospital Jena and was performed in accordance with the provisions of the Declaration of Helsinki.

\section{Patient treatment}

Induction chemotherapy was applied according to the $7+3$ regimen or according to the OSHO protocol. In detail, patients underwent induction chemotherapy with cytarabine $(100 \mathrm{mg} / \mathrm{sqm}$ as continuous 24 $\mathrm{h}$ infusion days 1-7) and daunorubicin (60 mg/sqm day 3-5) after inclusion in the DaunoDouble trial of the SAL study group.[36] According to the OSHO protocol, AML patients up to the age of 60 years were treated with idarubicin (12 mg/sqm, day 1-3) and intermediate-dosed cytarabine $(1 \mathrm{~g} / \mathrm{sqm}$ bid, day $1,3,5$ and 7) while patients over 60 years received mitoxantrone $(10 \mathrm{mg} / \mathrm{sqm}$, day $1-3)$ and intermediate-dosed cytarabine (1 g/sqm bid, days $1,3,5$ and 7$)$ as induction chemotherapy.[37,38]

HMA treatment consisted of either subcutaneously (s.c.) applied 5-Azacytidine $(75 \mathrm{mg} / \mathrm{sqm}$ day $1-7$ of a 28 -day cycle) or decitabine ( $20 \mathrm{mg} / \mathrm{sqm}$ day $1-5$ of a 28 -day cycle) administered intravenously while low-dosed cytarabine (LODAC) was given s.c. (e.g. $40 \mathrm{mg}$ day 1-7 every 4 weeks).

Best supportive care (BSC) regimens included infectious prophylaxis, treatment of infections and transfusion of blood products if indicated.

\section{Antimicrobial prophylaxis}

Standard regimens consisted of acyclovir ( $400 \mathrm{mg}$ BID) and cotrimoxazole (960 mg BID twice a week or $960 \mathrm{mg}$ three times a week). Antibacterial prophylaxis with ciprofloxacin (500 mg BID) and antifungal prophylaxis with either fluconazole (200 mg BID) or posaconazole (300 mg each day after a loading dose) was initiated in case of ANC below $1000 / \mu \mathrm{L}$ at diagnosis or under treatment, respectively. 


\section{Screening, diagnostic setup and empiric treatment}

Screening for relevant nosocomial pathogens (e.g. 3MRGN or VRE) was performed regularly. In case of fever, diagnostic work-up included physical examination, X-ray or mostly computed tomography of the chest and analysis of blood cultures, screening for urinary tract infections (UTI) and clinical evaluation of central venous catheters.

Standard therapy in patients with neutropenic fever consisted of immediate initiation of intravenous antibiotic treatment with piperacillin/tazobactam. In those patients previously screened positive of 3 MRGN or in case of hypotonic RR values despite rapid application of intravenous fluids with the necessity of vasopressors, antibiotic treatment was escalated to meropenem.

\section{Definition of neutropenia, neutropenic fever and analysis of toxicity}

Neutropenia was defined as absolute neutrophil count (ANC) below 1000/ $\mu \mathrm{L}$ and ANC was further categorized accordingly when ANC was below $500 / \mu \mathrm{L}$ or below $100 / \mu \mathrm{L}$. Neutropenic fever was characterized by a body temperature of higher than $38.3^{\circ} \mathrm{C}$ or of at least $38.0^{\circ} \mathrm{C}$ sustaining for one hour in the presence of absolute neutrophil counts less than 1000/ $\mu \mathrm{L}$.

\section{Definition of infectious events}

By means of clinical and microbiological investigation, sites of infection were classified, e.g. as blood stream infection, catheter-related infection or gastrointestinal (GI) tract infection. The following infectious complications analyzed in this study are described in more detail.

\section{Fever of unknown origin (FUO)}

Fever of unknown origin (FUO) was defined as fever according to the above defined criteria in the absence of an identifiable focus of infection provided that during the current fever episode no other site of infection could be defined later.

\section{Urinary tract infection (UTI)}

Urinary tract infections (UTI) were documented as "proven UTI" in case of at least $10^{5}$ colony-forming units (cfu) per $\mathrm{ml}$ in microbiological analyses or as "probable UTI" in symptomatic patients and at least $10^{4} \mathrm{cfu} / \mathrm{ml}$ but not exceeding $10^{5} \mathrm{cfu} / \mathrm{ml}$.

\section{Blood stream infections and sepsis criteria}

Blood cultures were routinely collected in case of fever and positive samples were monitored for antimicrobial susceptibility according to local laboratory protocols and standards. Positivity concerning skin pathogens was defined when peripheral and central venous line (CVL) blood cultures were tested positive. An infection of CVL in case of positive CVL and peripheral blood cultures (e.g. for Coagulasenegative Staphylococci, CoNS) was documented when time-to-positivity (TTP) was at least 2 hours shorter for CVL blood culture compared to peripheral blood culture unless peripheral samples were tested negative. The clinical event systemic inflammatory response syndrome (SIRS) and sepsis were defined according to the guidelines published by the German Sepsis Society in 2020.[39] 


\section{Classification of pneumonia and fungal infections}

Pneumonia was defined as a new infiltrate on chest radiograph (X-ray and/ or computed tomography) in combination with at least two of the following criteria: cough, sputum production, temperature $>38^{\circ} \mathrm{C}$ or $<35^{\circ} \mathrm{C}$, hemoptysis, thoracic pain or auscultatory findings consistent with pneumonia. Pneumonia was classified as atypical by radiographic criteria and pulmonary IFD was diagnosed based upon the criteria reported by the European Organization for Research and Treatment of Cancer/Invasive Fungal Infections Cooperative Group and the National Institute of Allergy and Infectious Diseases Mycoses Study Group (EORTC/MSG) in 2008.[15]

\section{Cytogenetic and molecular genetic analyses}

Karyotype analyses by means of chromosome banding were performed with standard techniques, and karyotypes were described according to the International System for Human Cytogenetic Nomenclature.[40] Cytogenetic categorization into favorable, intermediate or adverse risk was performed on the basis of recommended criteria.[41]

The presence of FLT3-ITD and NPM1 mutations was detected by PCR amplification of the corresponding region using genomic DNA followed by fragment analysis as previously described.[42]

Comprehensive molecular genetic analysis was performed in majority of AML patients undergoing intensive induction chemotherapy by next generation sequencing (NGS) enabling a reliable prognostic stratification according to the European LeukemiaNet (ELN )2017 classification.[43]

\section{Statistics}

In order to test the statistical significance of differences in categorical data we applied the Chi-square test while for continuous variables the Student's $t$-test was used. Differences between the KaplanMeier survival curves were evaluated by Log-rank (Mantel-Cox) test. P values of $<0.05$ were considered as statistically significant. Statistical analyses were performed using GraphPad Prism 8.0.2 (GraphPad Inc.). 


\section{Results}

\section{Patients' characteristics}

This analysis comprises 220 consecutive AML patients including 118 Patients who received palliative AML treatment and $102 \mathrm{AML}$ patients who underwent induction chemotherapy (Table 1). The median age (75 years; range 53-91 years) of AML patients receiving palliative treatment was significantly higher compared to AML patients with induction chemotherapy characterized by a median age of 61 years (range 25-76 years). The difference regarding age and the allocation to distinct treatment intensity associates with a significantly different distribution concerning the Eastern Collaborative Oncology Group (ECOG) performance status and the applied Charlson co-morbidity score between both patient subgroups. In detail, about half of AML patients (51.8\%) undergoing palliative treatment could be attributed to ECOG 2 or higher compared to only $26.5 \%$ in the subgroup of AML patients receiving induction chemotherapy. Furthermore, the modified Charlson co-morbidity score $(\mathrm{mCCl})$ directly correlated with the ECOG in both palliative AML patients $(\mathrm{mCCl} \leq 1$ in $52.5 \%$ of patients versus $\mathrm{mCCl} \geq 2$ in $47.5 \%$ of patients, respectively) and even more pronounced in those AML patients undergoing induction chemotherapy ( $\mathrm{mCCl} \leq 1$ in $78.4 \%$ of patients versus $\mathrm{mCCl} \geq 2$ in $21.6 \%$ of patients, respectively).

There was no significant difference between both AML subgroups concerning AML history, previous therapy with hypomethylating agents (HMA) or distribution of AML subtypes according to the FrenchAmerican-British (FAB) classification. Stratification according to the ELN 2017 classification revealed a significantly higher percentage of AML patients (25.5\%) that could not be classified as favorable compared to the subgroup of $A M L$ patients receiving palliative treatment ( $25.5 \%$ versus $13.6 \%, P 0.025)$.

Blood counts did not demonstrate any significant difference between both AML subgroups in terms of $\mathrm{WBC}, \mathrm{Hb}$ and platelet levels, bone marrow and peripheral blasts and especially with respect to absolute neutrophil counts (ANC) at AML primary diagnosis.

First line treatment of both AML subgroups is summarized in the supplemental Table S1. In detail, the majority of palliative AML patients (82.2\%) received HMA-based therapy either as single treatment or as combined treatment (e.g.; with the BCL-2 inhibitor venetoclax). Of patients receiving intensive $A M L$ therapy, 83 of $102(81.4 \%)$ were treated with single induction chemotherapy according to the $7+3$ schedule or the age-adapted OSHO protocol.

A detailed overview of AML patients receiving palliative treatment or undergoing induction chemotherapy, respectively, is provided in the CONSORT diagrams in the Supplement (Figure 1S and 2S), respectively.

\section{Infectious complication at diagnosis of AML}

A comprehensive analysis of all infections that were documented at the time of diagnosis and admission to the hospital was performed. Table 2 presents a classified overview of infectious complication at $A M L$ diagnosis for patients who were subsequently allocated to palliative treatment or induction chemotherapy of AML. Cumulative number of patients exceeds 118 patients in the palliative group and 102 patients who received induction chemotherapy, respectively, due to a possible overlap of infections or clinical situations (e.g., sepsis due to pneumonia). 
Patients allocated to palliative AML treatment presented a significantly higher probability of infections at diagnosis. In detail, 64 of 102 (62.7\%) patients consecutively undergoing induction chemotherapy had no clinical signs of infections while only 47 of 118 (39.8\%) of AML patients with palliative treatment presented without infections at diagnosis. In contrast, there was no difference concerning FUO, bloodstream infections and sepsis while more patients in the subgroup with subsequent palliative AML treatment had urinary tract infections (UTI) at diagnosis.

Detailed analysis of type of pneumonia especially considered the classification of potential invasive fungal disease (IFD) for all AML patients for this study. Significantly more patients attributed to palliative AML treatment did present with pneumonia at diagnosis of AML. Importantly, this observation does also translate in a significantly higher percentage of atypical pneumonia in these elderly $\mathrm{AML}$ patients. In detail, $37.3 \%$ of patients subsequently receiving palliative AML treatment presented with pneumonia including $22.0 \%$ of these patients with atypical pneumonia compared to $13.7 \%$ with pneumonia and $10.8 \%$ with atypical pneumonia, respectively, in the subgroup of AML patients allocated to induction chemotherapy.

Of note, the presence of infections at the time of AML diagnosis significantly correlates with the overall survival (OS) of palliative AML patients. In detail, the OS of elderly AML patients presenting without infectious complications at diagnosis was 315 days compared to only 69 days ( $P$ 0.0049) for patients with infections prior to start of palliative treatment in this intent-to-treat analysis (Figure 2).

\section{Antifungal strategies in both AML subgroups}

Table 2 summarizes both antifungal treatment in case of suspected IFD at diagnosis and different strategies of antifungal prophylaxis for both AML cohorts analyzed in this study. In detail, 12 of 14 patients subsequently allocated to palliative AML treatment presenting with pulmonary IFD could be evaluated for first-line antifungal therapy including 9 of these patients receiving secondary antifungal prophylaxis while 5 palliative AML patients fulfilling the criteria of pulmonary IFD died either early at diagnosis (two patients) or under treatment of pneumonia (three patients).

With respect to antifungal treatment, liposomal amphotericin was applied in the majority of AML patients with fungal pneumonia in the palliative AML patient cohort and in 2 of 4 patients with pulmonary IFD prior to AML induction chemotherapy.

According to the presentation with either possible or probable IFD, patients with fungal infections at diagnosis were treated with secondary antifungal prophylaxis that regularly consisted of posaconazole or voriconazole (Table 3). Primary antifungal prophylaxis effectively targeting Aspergillus spp. were applied in only 12 additional patients subsequently undergoing palliative therapy while the majority of patients within this AML subgroup received fluconazole prophylaxis in case of ANC below 1000 per $\mu$. In contrast, almost all AML patients treated with induction chemotherapy received primary prophylaxis with posaconazole being effective against Aspergillus spp. Thus, there was a significant difference in terms of primary antifungal prophylaxis between AML patients receiving palliative treatment and those patients consecutively undergoing AML induction chemotherapy.

\section{Infectious complications after initiation of AML treatment}

We next analyzed the spectrum of infectious complications after initiation of AML therapy in order to evaluate the impact of treatment intensity on the occurrence of severe infections in both AML 
treatment groups. The observation period was defined as follows: until day 100 after initiation of palliative AML treatment and until start of subsequent therapy (e.g. consolidation or allogeneic stem cell transplantation) following induction chemotherapy. 10 out of 118 AML patients of the palliative subgroup were lost of follow up, so that the analysis of consecutive infectious complications included 108 patients of this AML subgroup. Table 4 presents the comparison of infectious complications for AML patients either receiving palliative treatment or induction chemotherapy.

Surprisingly, after successful treatment of infectious complications presenting at AML diagnosis the majority of patients receiving palliative AML treatment (63.9\%) did not show further infectious complications until day 100 after initiation of AML therapy. This was significantly different compared to those AML patients with induction chemotherapy and does inversely correlate with the occurrence of both FUO and bloodstream infections. In detail, 60 out of 102 patients presented with at least one episode of FUO after initiation of induction chemotherapy and additional 35 patients had a bloodstream infection or fulfilled the criteria of sepsis $(n=11)$.

Importantly, the probability of bloodstream infections was significantly higher in the patient cohort undergoing induction chemotherapy as compared to those AML patients observed under palliative treatment. Positive blood samples were obtained in 40 patients resulting in 46 positive samples not considering two additional proven IFD each characterized by the detection of Candida glabrata blood stream infections. The spectrum of bacterial bloodstream infections for both AML treatment groups is shown in Figure S3. In detail, positive blood cultures detecting coagulase-negative Staphylococci spp. represent the major fraction in AML patients after induction chemotherapy while gut-associated bacteremia was due to both gram-negative and gram-positive pathogens. Importantly, Enterococci spp. isolated from blood culture specimens were exclusively tested positive for E. faecium in both AML treatment groups.

We next analyzed the impact of ANC on the frequency of clinically relevant infections in elderly patients. The potential impact of ANC at diagnosis on infectious complications in AML patients allocated to palliative treatment revealed no significant association for these patients at the time of AML diagnosis. Surprisingly, sepsis at diagnosis was only observed in those patients presenting with an ANC above 1000 per $\mu \mathrm{l}$. Exploring the frequency of infectious complications for the time interval between AML diagnosis and day 100 for palliative AML patients, the probability of consecutive infections in general and for the occurrence of FUO was significantly higher in case of ANC below 1000 per $\mu$ (Supplement, Table S2).

The occurrence of pneumonia after initiation of AML therapy dependent on the applied treatment intensity was also studied. In addition to Table 4, Figure 1 gives a detailed overview of distinct subsets of pneumonia documented either at diagnosis or after treatment initiation for both AML patient groups. A significantly higher rate of both pneumonia in general and atypical pneumonia in patients undergoing induction chemotherapy as compared to AML patients with palliative treatment is demonstrated: $51.0 \%$ versus $13.0 \%(P<0.001)$ and $49.0 \%$ versus $11.1 \%(P<0.001)$, respectively. Of note, the percentage of pulmonary IFD in the subgroup of atypical pneumonia is nearly identical between both patient subgroups at diagnosis - 14 of 26 patients (53.8\%) versus 6 of 11 patients (54.5\%), respectively - and does also reveal a comparable distribution after treatment initiation: 9 of 12 patients $(75.0 \%)$ versus 34 of 50 patients $(68.0 \%)$, respectively. There is a clinically relevant and significantly higher risk of pulmonary IFD in AML patients undergoing induction chemotherapy. In detail, we could observe a total of 34 patients with pulmonary IFD including one proven IFD (Rhizomucor spp.) in this treatment group (34 of 102 patients, 33.3\%) while only 9 Patients developed pulmonary IFD after initiation of palliative AML treatment ( 9 of 108 patients, $8.3 \%, P<0.001$ ). 
The analysis of additional infections revealed no significant difference for such infectious complications as UTI or soft tissue infections. Because all patients undergoing AML induction chemotherapy had a CVL catheter in contrast to only few palliative AML patients, the comparison of CVL infections between both subgroups is not applicable. Importantly, there was no venous thrombosis in case of CVL infection. Of note, there were three non-pulmonary IFD including the already described bloodstream infections with Candida glabrata and one patient with sinusitis due to a suspected fungal infection.

\section{ICU treatment and early mortality}

We next analyzed the necessity of intensive care unit (ICU) treatment for both AML treatment groups. An overview of distinct ICU indications (e.g. vasopressor therapy or mechanical ventilation) for AML patients either receiving palliative therapy or undergoing induction chemotherapy is given in Table 5 . In detail, 15 of 108 (13.9\%) palliative AML patients were admitted to ICU mainly because of septic shock $(n=7)$ or severe pneumonia $(n=4)$. In AML patients treated with induction chemotherapy, indication for ICU treatment was documented in 18 of 102 (17.6\%) patients including 7 patients with mechanical ventilation support due to severe pneumonia. Within the whole cohort of AML patients, 3 of 220 patients underwent leukapheresis. In 10 out of 15 (66.7\%) palliative AML patients and 15 of 18 $(83.3 \%)$ intensively treated AML patients, the acute clinical situation could be managed by ICU treatment enabling continuation of AML therapy.

The early death rate defined as the mortality until day 60 after initiation of either palliative AML treatment or induction chemotherapy significantly differed between both subgroups (Table 6). In patients undergoing intensive AML treatment a low early mortality rate of $3.9 \%$ was demonstrated. In detail, two of four patients died of pneumonia, while septic shock or life-threatening toxicity resulted in lethal outcome in one patient each. A female patient with therapy-related AML following anthracycline-containing breast cancer chemotherapy died during ICU treatment of sepsis with predominant heart failure assumed because of anthracycline-induced cardiotoxicity.

In contrast, 34 of 108 (31.5\%) evaluable AML patients starting palliative therapy died between treatment initiation (e.g., HMA-based therapy) and day 60. As expected, there was a broad spectrum of causes of death in the palliative subgroup of AML patients with a potential overlap between clinical complications and AML progression in three patients and co-occurrence of sepsis and pneumonia in another AML patient. The main cause of death was pneumonia (44.1\%) or sepsis (23.5\%, respectively. Of note, we observed a very low rate of IFD with respect to early mortality in elderly AML patients ( $2.9 \%$ at day 60 and $4.5 \%$ at day 100 , respectively).

\section{Impact of ECOG and co-morbidities on overall survival and infections}

In elderly AML patients, a significant impact of the ECOG performance status at the time of AML diagnosis on overall survival (OS) was detected. In detail, median OS for patients with ECOG 0 or 1 was 353 days (range 17-1165 days) compared to 50 days (range 2-1219 days) in patients presenting with ECOG 2 or higher, respectively (Figure 2, $P<0.001$ ). In contrast, stratifying the cohort of elderly AML patients with respect to co-morbidities ( $\mathrm{mCCl} \leq 1 \mathrm{vs}$. $\mathrm{mCCl} \geq 2$ ) revealed only a trend in favor of patients with a low $\mathrm{mCCl}$ score with respect to the observed difference in OS: 165 days (range 6-1165 days) vs. 112 days (range $2-1219$ days), respectively ( $P=0.0732$, Figure 2 ).

Furthermore, there was a clear and significant association of an ECOG performance score of at least 2 and the occurrence of pneumonia including atypical pneumonia and especially for pulmonary IFD (Supplement, Table S3). 


\section{Discussion}

Treatment of AML has been improved by recent supportive care concepts and implementation of new targeted therapies of AML. However, AML therapy remains challenging in both younger and elderly AML patients. Treatment-related mortality (TRM) following induction chemotherapy of AML could be substantially reduced during the last two decades, e.g., by improvement of antifungal prophylaxis with posaconazole. $[22,44]$

Furthermore, treatment options beyond conventional " $7+3$ " chemotherapy now consider mutationspecific or risk-adapted induction chemotherapy including midostaurin, gemtuzumab-ozogamicin or the liposomal application of cytarabine and daunorubicn (CPX-351).[45-47] In patients who are not eligible for intensive treatment, epigenetic approaches with hypomethylating agents (azacytidine or decitabine) have been established.[31,32] The addition of the BCL-2 inhibitor venetoclax can substantially improve the response rate and the overall survival of elderly AML patients as compared to single HMA treatment. [48,49]

We retrospectively analyzed a large cohort of consecutively treated AML patients at a tertiary hospital reflecting a series of AML patients mainly treated outside clinical trials. In this "intention-to-treat population" we focused on the presentation and development of infectious complications dependent on different treatment intensity and distinct approaches of antifungal prophylaxis.

Elderly patients presented significantly more frequent with infectious complications at the time of AML diagnosis predominantly caused by pneumonia. Therefore, we addressed the question whether either absolute neutrophil counts, the ECOG performance status or the extend of comorbidities correlate with infectious complications. That significant correlation between higher ECOG score and the occurrence of pneumonia including pulmonary IFD is most likely explained by an interdependence of both clinical factors potentially contributing to a worse outcome in patient cohort.[19] Our observation of a clinically relevant impact on overall survival with an inferior outcome of elderly AML patients presenting with infectious complications at diagnosis might explain the difference of median survival comparing results from clinical trials with such "real world" data as presented here.

Another potential factor for preexisting pneumonia at AML diagnosis might be attributed to an impaired function of innate immunity (e.g., in patients with antecedent MDS). Because there was no significant difference between our AML patient cohorts with respect to the percentage of de novo AML or hematological malignancies prior to AML diagnosis, respectively, we did not perform subgroup analysis focusing on this potential factor.[50,51]

In contrast, we could demonstrate a high rate of atypical pneumonia including a significantly higher proportion of pulmonary IFD in AML patients following induction chemotherapy. Several factors might contribute to the high incidence of pulmonary IFD in this well-defined cohort of AML patients: $1^{\text {st }}$, ANC are extremely low in AML patients undergoing induction chemotherapy; $2^{\text {nd }}$, the duration of severe neutropenia (ANC $<500$ per $\mu$ l); $3^{\text {rd }}$, the treatment-associated toxicity of conventional chemotherapy.

In detail, despite there was no significant difference concerning ANC at diagnosis between both AML patient groups, subsequent reduction of neutrophil counts can be expected to be much more pronounced after application of induction chemotherapy as compared to palliative AML treatment (e.g. with hypomethylating agents). Furthermore, the duration of usually undetectable neutrophils following induction chemotherapy depends on such important factors as age, antecedent hematological malignancy and especially on the response to the first induction cycle. $[19,52,53]$

In addition, the impact of treatment-related toxicity represents another factor that might contribute to a higher rate of pneumonia. Especially considering the presence of opportunistic pathogens (e.g. Aspergillus spp. or Pneumocystis jirovecii) at low levels in the bronchoalveolar system in combination 
with chemotherapy-induced pulmonary tissue damage might contribute to the high rate of atypical pneumonia.[54,55]

The especially high number of patients attributed to possible IFD according to the EORTC/MSG guidelines is also due to the strict diagnostic work-up in our AML population. In detail, all patients with neutropenic fever received at least one chest computed tomography scan with a high percentage of subsequent bronchoalveolar lavage (BAL) in case of pulmonary infiltrates. Both diagnostic strategies led to a high detection rate especially of possible IFD being classified by characteristic infiltrates or a combination with distinct clinical symptoms while the cumulative incidence of proven and probable IFD was well comparable with recently published studies.[56-58]

Of note, significantly less patients presented with infections after initiation of palliative AML treatment compared to the cohort receiving induction chemotherapy. Both the occurrence of febrile neutropenia or bacteremia and the observation of a significantly higher incidence of pneumonia including pulmonary IFD following induction chemotherapy could also be demonstrated by Jalbut and colleagues analyzing a cohort of $172 \mathrm{AML}$ patients. [33] To our best knowledge, this study represents one of the most comprehensive comparisons of infectious complication in AML patients either receiving palliative treatment or induction chemotherapy.

The fact that most patients undergoing palliative AML treatment did not receive Aspergillus spp.-directed antifungal prophylaxis should not lead to the conclusion that posaconazole prophylaxis is not reasonable in this subset of $A M L$ patients. Nevertheless, in a recently published study investigating fungal infections in AML patients treated with HMA and venetoclax, there was a low risk of fungal infections not affected by different antifungal strategies.[59]

Analysis of pathogens in positive blood stream specimens revealed a high percentage of coagulasenegative Staphylococci spp. in those patients undergoing AML induction chemotherapy correlating with the application and potential infection of central venous catheters. Considering coagulase-negative Staphylococci spp. there was a higher rate of blood stream infections compared to a large cohort of AML patients published by Conn and colleagues.[5] The detection of Enterococci spp. in blood stream samples was restricted to $E$. faecium being of clinical relevance with respect to the empiric antibiotic strategies in neutropenic patients. The observation that gram-positive pathogens were most frequently detected in culture-positive blood samples has also been shown in a large series of AML and MDS patients treated with decitabine previously published by Ali and co-workers. [60]

We did also analyze the spectrum of indications and the outcome after ICU treatment in both AML patient subgroups. Even in patients receiving palliative AML treatment ICU treatment had a favorable short-term outcome in two thirds of patients necessitating ICU treatment. This provides a clear rationale to include ICU regimens in certain clinical situations despite a palliative treatment approach. Especially time-limited vasopressor therapy should be considered in case of sepsis in elderly AML patients enabling either bridging to initiation or continuation of AML therapy in these patients. This is in line with previous reports analyzing the impact of ICU treatment approaches in AML patients. [61,62]

The decision which treatment intensity should be applied to an elderly AML patient should be made based on individual factors including age, comorbidity, performance status, etiological and genetic features of AML. Furthermore, a higher rate of early death following induction chemotherapy because of treatment-related complications (e.g., severe infections) has been observed.[63] Of note, retrospective comparison of induction chemotherapy versus HMA-based treatment in elderly AML patients demonstrated a similar outcome due to a higher early death rate following induction chemotherapy.[64]

Taken together, we demonstrate a distinct pattern of infectious complications in AML patients at diagnosis and dependent on their subsequent allocation to different treatment modalities. Despite a 
potentially effective Aspergillus spp.-directed antifungal prophylaxis in patients undergoing AML induction chemotherapy, one should be aware of the remaining and relevant risk of pulmonary IFD in this clinical setting. In general, a strict diagnostic work-up in AML patients with neutropenic fever as well as a clear classification of pneumonia are essential for optimized treatment of infectious complications in this highly vulnerable patient cohort. In addition, a palliative treatment approach should also allow a well-balanced decision for intensive care in elderly patients. 


\section{TABLES AND FIGURES}

Table 1: $\quad$ Patients characteristics at diagnosis of AML for patients receiving palliative treatment or AML induction chemotherapy.

Table 2: $\quad$ Spectrum of infectious complications at diagnosis of AML for both patient subgroups.

Table 3: Antifungal strategies at diagnosis dependent on subsequent AML treatment intensity.

Table 4: $\quad$ Comparison of infectious complications after initiation of palliative AML treatment (until day 100) or following AML induction chemotherapy.

Table 5: $\quad$ ICU treatment indications and short-term outcome in AML patients of both subgroups.

Table 6: $\quad$ Mortality until day 60 after AML diagnosis for each treatment group.

Figure 1: $\quad$ CONSORT diagram of time-dependent pneumonia subtypes for both patient groups

Figure 2: $\quad$ Kaplan-Meier plots for AML patients undergoing palliative treatment dependent on ECOG score (A), infections at diagnosis (B) or Charlson comorbidity index (C)

\section{SUPPLEMENT}

Table S1: $\quad$ Overview of first line AML therapy for both patient subgroups

Table S2: $\quad$ Occurrence of infections dependent on ANC prior to palliative AML treatment

Table S3: $\quad$ Occurrence of infections dependent on ECOG prior to palliative AML treatment

Figure S1: $\quad$ CONSORT diagram of AML patients $(n=118)$ with palliative treatment

Figure S2: CONSORT diagram of AML patients ( $n=102)$ with induction chemotherapy

Figure S3: $\quad$ Spectrum of pathogens obtained from blood culture samples dependent on AML treatment intensity 


\begin{tabular}{|c|c|c|c|}
\hline & $\begin{array}{l}\text { Palliative } \\
\text { treatment } \\
\mathrm{N}=118\end{array}$ & $\begin{array}{l}\text { Induction } \\
\text { chemotherapy } \\
\qquad N=102\end{array}$ & $P$ \\
\hline Median age at diagnosis, years (range) & $75(53-91)$ & $61(25-76)$ & $<0.001$ \\
\hline Female patients, $\mathrm{n}(\%)$ & $53(44.9)$ & $57(55.9)$ & n.s. \\
\hline $\begin{array}{l}\text { Performance status, } n(\%) \\
\text { ECOG } \leq 1 \\
\text { ECOG } \geq 2\end{array}$ & $\begin{array}{l}58(49.2) \\
60(51.8)\end{array}$ & $\begin{array}{l}75(73.5) \\
27(26.5)\end{array}$ & $<0.001$ \\
\hline $\begin{aligned} & \text { Co-morbidity index, } \mathrm{n}(\%) \\
& \mathrm{mCCl} \leq 1 \\
& \mathrm{mCCl} \geq 2\end{aligned}$ & $\begin{array}{l}62(52.5) \\
56(47.5)\end{array}$ & $\begin{array}{l}80(78.4) \\
22(21.6)\end{array}$ & $<0.001$ \\
\hline $\begin{array}{l}\text { WBC, per } \mu \mathrm{L} \text { (range) } \\
\mathrm{Hb}, \mathrm{mmol} / \mathrm{L} \text { (range) } \\
\mathrm{PLT} \text {, per } \mu \mathrm{L} \text { (range) } \\
\text { ANC, per } \mu \mathrm{L} \text { (range) }\end{array}$ & $\begin{array}{c}7.6(0.5-320) \\
5.4(2.4-8.4) \\
54(0-297) \\
1600(0-62300)\end{array}$ & $\begin{array}{c}8,7(0.6-331) \\
5,6(2.8-9.2) \\
62.5(6-864) \\
1270(60-55000)\end{array}$ & n.s. \\
\hline $\begin{array}{l}\text { Percentage of blasts, \% (range) } \\
\text { Peripheral blood } \\
\text { Bone marrow }\end{array}$ & $\begin{array}{c}12(0-89) \\
53(20-95)\end{array}$ & $\begin{array}{c}20(0-96) \\
60(20-98)\end{array}$ & n.s. \\
\hline $\begin{array}{l}\text { FAB subtype, } \mathrm{n}(\%) \\
\mathrm{M} 1 / \mathrm{M} 2 \\
\mathrm{M} 4 / \mathrm{M} 5 \\
\mathrm{M} 6\end{array}$ & $\begin{array}{c}81(68.6) \\
35(29.7) \\
2(1.7) \\
\end{array}$ & $\begin{array}{c}66(64.7) \\
34(33.3) \\
2(1.9) \\
\end{array}$ & n.s. \\
\hline $\begin{array}{l}\text { History of } A M L \\
\text { de novo } A M L \\
\text { antecedent MDS } \\
\text { antecedent CMML or MPN } \\
\text { therapy-related AML }\end{array}$ & $\begin{array}{c}60(50.8) \\
29(24.6) \\
23(19.5) \\
6(5.1) \\
\end{array}$ & $\begin{array}{c}58(56.9) \\
24(23.5) \\
14(13.7) \\
6(5.9) \\
\end{array}$ & n.s. \\
\hline $\begin{array}{l}\text { Previous therapy of MDS, CMML or MPN, } n \text { (\%) } \\
\text { HMA } \\
\text { Ruxolitinib and/ or hydroxyurea } \\
\text { Lenalidomide } \\
\text { ASCT }\end{array}$ & $\begin{array}{c}16(13.6) \\
8(6.8) \\
- \\
-\end{array}$ & $\begin{array}{c}18(17.6) \\
4(3.9) \\
1(1) \\
2(2) \\
\end{array}$ & n.s. \\
\hline $\begin{array}{l}\text { ELN } 2017 \text { risk group, } \mathrm{n}(\%) \\
\text { favorable } \\
\text { intermediate } \\
\text { unfavorable } \\
\text { not available }\end{array}$ & $\begin{array}{l}16(13.6) \\
41(34.7) \\
39(33.1) \\
22(18.6)\end{array}$ & $\begin{array}{c}26(25.5) \\
30(29.4) \\
44(43.1) \\
2(2)\end{array}$ & 0.025 \\
\hline
\end{tabular}

Table 1: Patients' characteristics at diagnosis of AML for patients receiving palliative treatment or AML induction chemotherapy. Abbreviations: AML, acute myeloid leukemia; ANC, absolute neutrophil count; ASCT, allogeneic stem cell transplantation; $\mathrm{CCl}$, Charlson comorbidity index; $\mathrm{CMML}$, chronic myelomonocytic leukemia; FAB, French-American-British classification; ECOG, Eastern Cooperative oncology Groups score; ELN, European LeukemiaNET classification; $\mathrm{Hb}$, hemoglobin level; HMA, hypomethylating agent; MDS, myelodysplastic syndrome; MPN, myeloproliferative neoplasia; PLT, platelet count; WBC, white blood count 


\begin{tabular}{|l|c|c|c|}
\hline & Palliative Treatment & Induction chemotherapy & $P$ \\
& $\mathrm{~N}=118$ & $\mathrm{~N}=102$ & value \\
\hline Patients without infections, $\mathrm{n}(\%)$ & $47(39.8)$ & $64(62.7)$ & $<0.001$ \\
\hline FUO, $\mathrm{n}(\%)$ & $14(11.9)$ & $17(16.7)$ & $n . s$. \\
\hline Bloodstream infection, $\mathrm{n}(\%)$ & $1(0.8)$ & $1(1)$ & $n .5$. \\
\hline Sepsis, $\mathrm{n}(\%)$ & $5(4.2)$ & $2(2)$ & n.s. \\
\hline Pneumonia & $44(37.3)$ & $14(13.7)$ & \\
typical Pneumonia & $18(15.3)$ & $3(2.9)$ & \\
atypical pneumonia & $26(22.0)$ & $11(10.8)$ & \\
\hline Atypical pneumonia & $26(22.0)$ & $11(10.8)$ & \\
no IFD & $12(10.2)$ & $5(4.9)$ & \\
Possible IFD & $13(11.0)$ & $6(5.9)$ & 0.026 \\
Probable IFD & $1(0.8)$ & 0 & \\
\hline Other infections & & - & \\
Urinary tract infection & $6(5.1)$ & - & \\
Endocarditis & $1(0.8$ & - & \\
Bronchitis & $1(0.8)$ & $3(2.9)$ & - \\
Oropharyngeal infection & - & $3(2.9)$ & \\
Clostridium difficile enteritis & $1(0.8)$ & & \\
Soft tissue infection & $1(0.8)$ & & \\
\hline
\end{tabular}

Table 2: Spectrum of infectious complications at diagnosis of AML for both patient subgroups.

Abbreviations: FUO, fever of unknown origin; IFD, invasive fungal disease 


\begin{tabular}{|l|c|c|}
\hline & Palliative Treatment & Induction chemotherapy \\
& $\mathrm{N}=118$ & $\mathrm{~N}=102$ \\
\hline Antifungal prophylaxis after AML & & \\
diagnosis & $9(7.6)$ & \\
After IFD, $n$ (\%) & $2(1.7)$ & $4(3.9)$ \\
Posaconazole & $4(3.4)$ & $4(3.9)$ \\
Voriconazole & $2(1.7)$ & - \\
Isavuconazole & $1(0.8)$ & - \\
No prophylaxis & $12(10.2)$ & - \\
w/o IFD, $n$ (\%) & $11(9.3)$ & 95 \\
Posaconazole & $1(0.8)$ & - \\
Voriconazole & - & $1(1)$ \\
Isavuconazol & $6(5.1)$ & $2(2)$ \\
\hline $1^{\text {st line antifungal treatment }}$ & $4(3.4)$ & - \\
Liposomal amphotericin & $2(1.7)$ & - \\
Caspofungin & $2(1.7)$ & $2(2)$ \\
Posaconazole & & \\
Voriconazole & & \\
\hline
\end{tabular}

Table 3: Antifungal strategies at diagnosis dependent on subsequent AML treatment intensity.

Abbreviations: AML, acute myeloid leukemia; IFD, invasive fungal disease 


\begin{tabular}{|c|c|c|c|}
\hline & $\begin{array}{l}\text { AML palliative } \\
\text { until day } 100 \\
\qquad N=108\end{array}$ & $\begin{array}{l}\text { AML intensive } \\
\text { after induction } \\
\qquad N=102\end{array}$ & $\begin{array}{c}P \\
\text { value }\end{array}$ \\
\hline Patients without infections, n (\%) & $69(63.9)$ & $2(2.0)$ & $<0.001$ \\
\hline FUO, n (\%) & $9(8.3)$ & $60(58.8)$ & $<0.001$ \\
\hline Bloodstream infection, n (\%) & $1(0.9)$ & $35(34.3)$ & $<0.001$ \\
\hline Sepsis, n (\%) & $6(5.6)$ & $11(10.8)$ & n.s. \\
\hline $\begin{array}{l}\text { Pneumonia, } \mathrm{n}(\%) \\
\text { typical Pneumonia } \\
\text { atypical pneumonia }\end{array}$ & $\begin{aligned} & 14(13.0) \\
& 2(1.9) \\
& 12(11.1) \\
&\end{aligned}$ & $\begin{array}{c}52(51.0) \\
2(2.0) \\
50(49.0) \\
\end{array}$ & $<0.001$ \\
\hline $\begin{array}{l}\text { Atypical pneumonia, } \mathrm{n}(\%) \\
\text { no IFD } \\
\text { Possible IFD } \\
\text { Probable IFD } \\
\text { Proven IFD } \\
\end{array}$ & $\begin{array}{c}12(11.1) \\
3(2.8) \\
6(5.6) \\
3(2.8) \\
0 \\
\end{array}$ & $\begin{array}{c}50(49.0) \\
16(15.7) \\
25(24.5) \\
8(7.8) \\
1(1.0) \\
\end{array}$ & $\begin{array}{l}<0.001 \\
<0.001\end{array}$ \\
\hline $\begin{array}{l}\text { Other infections, } \mathrm{n}(\%) \\
\text { Urinary tract infection } \\
\text { Oropharyngeal infections } \\
\text { Mediastinitis } \\
\text { Bronchitis } \\
\mathrm{Cl} \text {. difficile enteritis } \\
\text { Soft tissue infection } \\
\mathrm{CVL} \text { infections } \\
\text { Non-pulmonary IFDs } \\
\text { Possible IFD } \\
\text { Proven IFD } \\
\end{array}$ & $\begin{array}{c}7(6.5) \\
0 \\
0 \\
1(0.9) \\
1(0.9) \\
2(1.9) \\
1(0.9) \\
\\
1(0.9) \\
- \\
\end{array}$ & $\begin{array}{c}13(12.7) \\
7(6.9) \\
1(1.0) \\
0 \\
2(2.0) \\
6(5.9) \\
37(36.3) \\
\\
- \\
2(2.0)\end{array}$ & n.s. \\
\hline
\end{tabular}

Table 4: Infectious complications following palliative AML treatment (until day 100) or AML induction chemotherapy. Abbreviations: CVL, central venous line; FUO, fever of unknown origin; IFD, invasive fungal disease; n.s., not significant; n.a. not applicable 


\begin{tabular}{|c|c|c|}
\hline ICU indication & $\begin{array}{l}\text { Palliative Treatment } \\
\qquad N=108\end{array}$ & $\begin{array}{l}\text { Induction chemotherapy } \\
\qquad N=102\end{array}$ \\
\hline Sepsis & $\begin{array}{l}\text { death } n=1 \\
\text { resolved } n=6\end{array}$ & $\begin{array}{c}\text { death } n=1 \\
\text { resolved } n=1\end{array}$ \\
\hline Pneumonia & $\begin{array}{c}\text { death } n=3 \\
\text { resolved } n=1\end{array}$ & $\begin{array}{c}\text { death } n=1 \\
\text { resolved } n=6\end{array}$ \\
\hline $\begin{array}{l}\text { Neurological / neurosurgical } \\
\text { complications }\end{array}$ & resolved $n=2$ & resolved $n=3$ \\
\hline Pulmonary bleeding & death $n=1$ & - \\
\hline Leukapheresis & resolved $n=1$ & resolved $n=2$ \\
\hline Toxicity / organ failure & - & $\begin{array}{c}\text { death } n=1 \\
\text { resolved } n=2\end{array}$ \\
\hline Splenectomy & - & resolved $n=1$ \\
\hline Overall & $\begin{array}{c}\text { resolved } n=10 \\
\text { death } n=5\end{array}$ & $\begin{array}{c}\text { resolved } n=15 \\
\text { death } n=3\end{array}$ \\
\hline Mortality & $\begin{array}{c}5 \text { of } 15 \text { patients } \\
(33.3 \%)\end{array}$ & $\begin{array}{c}3 \text { of } 18 \text { patients } \\
(16.7 \%)\end{array}$ \\
\hline
\end{tabular}

Table 5: Intensive care unit (ICU) treatment indications and short-term outcome in AML patients of both subgroups.

\begin{tabular}{|l|c|c|}
\hline & $\begin{array}{c}\text { Palliative Treatment } \\
\mathrm{N}=108\end{array}$ & $\begin{array}{c}\text { Induction chemotherapy } \\
\mathrm{N}=102\end{array}$ \\
\hline Mortality & $34 / 108(31.5 \%)$ & $4 / 102(3.9 \%)$ \\
\hline Predominant progression of AML & $8 / 34(23.5 \%)$ & - \\
\hline Pneumonia & $15 / 34(44.1 \%)$ & $2(50 \%)$ \\
No IFD & $11 / 34(32.4 \%)$ & - \\
IFD & $1 / 34(2.9 \%)$ & $1(50 \%)$ \\
with AML progression & $3 / 34(8.8 \%)$ & $1(50 \%)$ \\
\hline Sepsis & $8 / 34(23.5 \%)$ & $1(25 \%)$ \\
w/o pneumonia & $7 / 34(20.6)$ & - \\
with pneumonia & $1 / 34(2.9 \%)$ & $1(25 \%)$ \\
\hline Bleeding & $3 / 34(8.8 \%)$ & \\
\hline Toxicity & - & \\
\hline
\end{tabular}

Table 6: Mortality until day 60 after AML diagnosis for each treatment group 


\section{SUPPLEMENT}

\begin{tabular}{|l|c|c|}
\hline & $\begin{array}{c}\text { Palliative Treatment } \\
\mathrm{N}=118\end{array}$ & $\begin{array}{c}\text { Induction chemotherapy } \\
\mathrm{N}=102\end{array}$ \\
\hline $\begin{array}{l}\text { Cytoreductive chemotherapy, } \mathrm{n}(\%) \\
\text { Hydroxyurea }\end{array}$ & $43(36.4)$ & $48(47.1)$ \\
Cytarabine & $26(22.0)$ & $23(22.6)$ \\
\hline $1^{\text {st }}$ line treatment of AML, $\mathrm{n}(\%)$ & $17(14.4)$ & \\
HMA-based & $97(82.2)$ & \\
LODAC-based & $14(11.9)$ & \\
Dasatinib & $1(0.8)$ & \\
BSC only & $6(5.1)$ & $24(23.5)$ \\
\hline $1^{\text {st }}$ line treatment of AML, $\mathrm{n}(\%)$ & & $18(17.7)$ \\
single 7+3 induction & & $15(14.7)$ \\
double 7+3 induction & & $44(43.1)$ \\
OSHO $\leq 60$ years & & $1(1)$ \\
OSHO $>60$ years & & $11(10.8)$ \\
CPX-351 & & \\
Salvage induction with MitoFLAG & & \\
\hline
\end{tabular}

Table S1: Overview of first line AML therapy for both patient subgroups. Abbreviations: BSC, best supportive care; CPX-351, liposomal formulation of induction chemotherapy $\left(V_{y x e o s^{R}}\right)$; HMA, hypomethylating agent; LODAC, low-dosed cytarabine; OSHO, East German Study Group of Hematology and Oncology 


\begin{tabular}{|c|c|c|c|c|c|c|}
\hline \multirow[b]{2}{*}{$N=108$} & \multicolumn{3}{|c|}{ at diagnosis } & \multicolumn{3}{|c|}{ until day 100} \\
\hline & $\begin{array}{c}\text { ANC }<1000 \\
\quad \operatorname{per} \mu \mathrm{L} \\
\mathrm{N}=43\end{array}$ & $\begin{array}{c}A N C \geq 1000 \\
\text { per } \mu \mathrm{L} \\
N=65\end{array}$ & $P$ & $\begin{array}{c}\text { ANC }<1000 \\
\quad \operatorname{per} \mu \mathrm{L} \\
\mathrm{N}=43\end{array}$ & $\begin{array}{c}A N C \geq 1000 \\
\quad \operatorname{per} \mu \mathrm{L} \\
N=65\end{array}$ & $P$ \\
\hline $\begin{array}{l}\text { Patients without } \\
\text { infections, } \mathrm{n}(\%)\end{array}$ & $18(41.9)$ & $23(35.4)$ & n.s. & $19(44.2)$ & $50(77.0)$ & $<0.001$ \\
\hline FUO, n (\%) & 5 (11.6) & $6(9.2)$ & n.s. & $6(14.0)$ & $1(1.5)$ & 0.01 \\
\hline $\begin{array}{l}\text { Bloodstream } \\
\text { infection, n (\%) }\end{array}$ & $1(2.3)$ & 0 & n.s. & $1(2.3)$ & 0 & n.s. \\
\hline Sepsis, n (\%) & 0 & $5(7.7)$ & 0.062 & $4(9.3)$ & $2(3.1)$ & n.s. \\
\hline $\begin{array}{l}\text { Pneumonia, n (\%) } \\
\text { typical Pneumonia } \\
\text { atypical pneumonia }\end{array}$ & $\begin{array}{l}13(30.2) \\
5(11.6) \\
9(20.9)\end{array}$ & $\begin{array}{l}27(41.5) \\
13(20.0) \\
14(21.5) \\
\end{array}$ & n.s. & $\begin{array}{l}6(14.0) \\
4(9.3) \\
2(4.7)\end{array}$ & $\begin{array}{l}5(7.7) \\
2(3.1) \\
3(4.6)\end{array}$ & n.s. \\
\hline $\begin{array}{l}\text { Atypical pneumonia, } \mathrm{n}(\%) \\
\text { no IFD } \\
\text { Possible IFD } \\
\text { Probable IFD }\end{array}$ & $\begin{array}{c}9(20.9) \\
3(7.0) \\
5(11.6) \\
1(2.3)\end{array}$ & $\begin{array}{c}14(21.5) \\
8(12.3) \\
6(9.2) \\
0\end{array}$ & n.s. & $\begin{array}{l}2(4.7) \\
0 \\
1(2.3) \\
1(2.3)\end{array}$ & $\begin{array}{l}2(3.1) \\
0 \\
2(3.1) \\
1(1.5)\end{array}$ & n.s. \\
\hline
\end{tabular}

Table S2: Occurrence of Infectious complications dependent on ANC until day 100 of palliative AML therapy

\begin{tabular}{|l|c|c|c|}
\hline \multicolumn{1}{|c|}{$\mathrm{N}=108$} & $\mathrm{ECOG} \leq 1$ & $\mathrm{ECOG} \geq 2$ & $P$ \\
& $\mathrm{~N}=50$ & $\mathrm{~N}=58$ & \\
\hline Patients without infections, $\mathrm{n}(\%)$ & $31(62.0)$ & $10(17.2)$ & $<0.001$ \\
\hline FUO, $\mathrm{n}(\%)$ & $7(14.0)$ & $4(6.9)$ & n.s. \\
\hline Bloodstream infection, $\mathrm{n}(\%)$ & $1(2.0)$ & 0 & n.s. \\
\hline Sepsis, $\mathrm{n}(\%)$ & $1(2.0)$ & $4(6.9)$ & n.s. \\
\hline Pneumonia, $\mathrm{n}$ (\%) & $7(14.0)$ & $33(56.9)$ & $<0.001$ \\
typical Pneumonia & $5(10.0)$ & $13(22.4)$ & \\
atypical pneumonia & $2(4.0)$ & $21(36.2)$ & \\
\hline Atypical pneumonia, $\mathrm{n}(\%)$ & $2(4.0)$ & $21(36.2)$ & $<0.001$ \\
no IFD & $2(4.0)$ & $9(15.5)$ & \\
Possible IFD & 0 & $11(19.0)$ & \\
Probable IFD & 0 & $1(1.7)$ & \\
\hline
\end{tabular}

Table S3: Occurrence of Infectious complications dependent on ECOG at diagnosis 


\section{FIGURE LEGENDS}

Figure 1: CONSORT diagram of time-dependent pneumonia subtypes for both patient groups. Distribution of absolute numbers of patients presenting with pneumonia either at the time of $A M L$ diagnosis (upper part) or after initiation of AML therapy (lower part) for patients allocated to palliative AML treatment (left) or induction chemotherapy (right).

Figure 2: Kaplan-Meier estimates for overall survival (OS) dependent on the ECOG performance score (A) or on the modified Charlson comorbidity index (B) for AML patients undergoing palliative treatment.

\section{SUPPLEMENT}

Figure S1: CONSORT diagram of AML patients $(n=118)$ with palliative treatment. Illustration of antecedent hematological disease or specific therapy prior to diagnosis of AML and distribution of firstline AML therapy in patients allocated to palliative AML treatment.

Figure S2: CONSORT diagram of AML patients $(n=102)$ with induction chemotherapy. Overview of antecedent hematological disease or specific therapy prior to diagnosis of $A M L$, distribution of hematological response and subsequent treatment of patients undergoing induction chemotherapy as first-line treatment of AML.

Figure S3: Spectrum of pathogens obtained from blood culture samples dependent on AML treatment intensity. Distribution of positive blood culture specimens indicating the spectrum of isolated bacteria in febrile patients after palliative AML treatment (A) or following induction chemotherapy (B). 


\section{References}

1. Fernandez, H.F.; Sun, Z.; Yao, X.; Litzow, M.R.; Luger, S.M.; Paietta, E.M.; Racevskis, J.; Dewald, G.W.; Ketterling, R.P.; Bennett, J.M., et al. Anthracycline dose intensification in acute myeloid leukemia. N Engl J Med 2009, 361, 1249-1259, doi:10.1056/NEJMoa0904544.

2. Classen, A.Y.; Henze, L.; von Lilienfeld-Toal, M.; Maschmeyer, G.; Sandherr, M.; Graeff, L.D.; Alakel, N.; Christopeit, M.; Krause, S.W.; Mayer, K., et al. Primary prophylaxis of bacterial infections and Pneumocystis jirovecii pneumonia in patients with hematologic malignancies and solid tumors: 2020 updated guidelines of the Infectious Diseases Working Party of the German Society of Hematology and Medical Oncology (AGIHO/DGHO). Ann Hematol 2021, 100, 1603-1620, doi:10.1007/s00277-021-04452-9.

3. Walter, R.B.; Othus, M.; Borthakur, G.; Ravandi, F.; Cortes, J.E.; Pierce, S.A.; Appelbaum, F.R.; Kantarjian, H.A.; Estey, E.H. Prediction of early death after induction therapy for newly diagnosed acute myeloid leukemia with pretreatment risk scores: a novel paradigm for treatment assignment. J Clin Oncol 2011, 29, 4417-4423, doi:10.1200/jco.2011.35.7525.

4. Atallah, E.; Cortes, J.; O'Brien, S.; Pierce, S.; Rios, M.B.; Estey, E.; Markman, M.; Keating, M.; Freireich, E.J.; Kantarjian, H. Establishment of baseline toxicity expectations with standard frontline chemotherapy in acute myelogenous leukemia. Blood 2007, 110, 3547-3551, doi:10.1182/blood-2007-06-095844.

5. Conn, J.R.; Catchpoole, E.M.; Runnegar, N.; Mapp, S.J.; Markey, K.A. Low rates of antibiotic resistance and infectious mortality in a cohort of high-risk hematology patients: A single center, retrospective analysis of blood stream infection. PLoS One 2017, 12, e0178059, doi:10.1371/journal.pone.0178059.

6. Malagola, M.; Peli, A.; Damiani, D.; Candoni, A.; Tiribelli, M.; Martinelli, G.; Piccaluga, P.P.; Paolini, S.; De Rosa, F.; Lauria, F., et al. Incidence of bacterial and fungal infections in newly diagnosed acute myeloid leukaemia patients younger than $65 \mathrm{yr}$ treated with induction regimens including fludarabine: retrospective analysis of 224 cases. Eur J Haematol 2008, 81, 354-363, doi:10.1111/j.1600-0609.2008.01122.x.

7. Marin, M.; Gudiol, C.; Ardanuy, C.; Garcia-Vidal, C.; Calvo, M.; Arnan, M.; Carratalà, J. Bloodstream infections in neutropenic patients with cancer: differences between patients with haematological malignancies and solid tumours. J Infect 2014, 69, 417-423, doi:10.1016/j.jinf.2014.05.018.

8. Legrand, M.; Max, A.; Peigne, V.; Mariotte, E.; Canet, E.; Debrumetz, A.; Lemiale, V.; Seguin, A.; Darmon, M.; Schlemmer, B., et al. Survival in neutropenic patients with severe sepsis or septic shock. Crit Care Med 2012, 40, 43-49, doi:10.1097/CCM.0b013e31822b50c2.

9. Sostarich, A.M.; Zolldann, D.; Haefner, H.; Luetticken, R.; Schulze-Roebecke, R.; Lemmen, S.W. Impact of multiresistance of gram-negative bacteria in bloodstream infection on mortality rates and length of stay. Infection 2008, 36, 31-35, doi:10.1007/s15010-007-6316-4.

10. Ballo, O.; Tarazzit, I.; Stratmann, J.; Reinheimer, C.; Hogardt, M.; Wichelhaus, T.A.; Kempf, V.; Serve, H.; Finkelmeier, F.; Brandts, C. Colonization with multidrug resistant organisms determines the clinical course of patients with acute myeloid leukemia undergoing intensive induction chemotherapy. PLoS One 2019, 14, e0210991, doi:10.1371/journal.pone.0210991.

11. Garcia, J.B.; Lei, X.; Wierda, W.; Cortes, J.E.; Dickey, B.F.; Evans, S.E.; Ost, D.E. Pneumonia during remission induction chemotherapy in patients with acute leukemia. Ann Am Thorac Soc 2013, 10, 432-440, doi:10.1513/AnnalsATS.201304-0970C.

12. Specchia, G.; Pastore, D.; Carluccio, P.; Mele, G.; Montagna, M.T.; Liso, A.; Rizzi, R.; lanora, A.S.; Liso, V. Pneumonia in acute leukemia patients during induction therapy: experience in a single institution. Leuk Lymphoma 2003, 44, 97-101, doi:10.1080/1042819021000040297.

13. Gerritsen, M.G.; Willemink, M.J.; Pompe, E.; van der Bruggen, T.; van Rhenen, A.; Lammers, J.W.J.; Wessels, F.; Sprengers, R.W.; de Jong, P.A.; Minnema, M.C. Improving early diagnosis of pulmonary infections in patients with febrile neutropenia using low-dose chest computed tomography. PloS one 2017, 12, e0172256-e0172256, doi:10.1371/journal.pone.0172256. 
14. Maschmeyer, G.; Carratalà, J.; Buchheidt, D.; Hamprecht, A.; Heussel, C.P.; Kahl, C.; Lorenz, J.; Neumann, S.; Rieger, C.; Ruhnke, M., et al. Diagnosis and antimicrobial therapy of lung infiltrates in febrile neutropenic patients (allogeneic SCT excluded): updated guidelines of the Infectious Diseases Working Party (AGIHO) of the German Society of Hematology and Medical Oncology (DGHO). Ann Oncol 2015, 26, 21-33, doi:10.1093/annonc/mdu192.

15. De Pauw, B.; Walsh, T.J.; Donnelly, J.P.; Stevens, D.A.; Edwards, J.E.; Calandra, T.; Pappas, P.G.; Maertens, J.; Lortholary, O.; Kauffman, C.A., et al. Revised definitions of invasive fungal disease from the European Organization for Research and Treatment of Cancer/Invasive Fungal Infections Cooperative Group and the National Institute of Allergy and Infectious Diseases Mycoses Study Group (EORTC/MSG) Consensus Group. Clin Infect Dis 2008, 46, 1813-1821, doi:10.1086/588660.

16. Livio, P.; Morena, C.; Anna, C.; Massimo, O.; Bruno, M.; Giorgina, S.; Domenico, P.; Marta, S.; Chiara, C.; Rosa, F., et al. Invasive aspergillosis in patients with acute myeloid leukemia: a SEIFEM-2008 registry study. Haematologica 2010, 95, 644-650, doi:10.3324/haematol.2009.012054.

17. Hammond, S.P.; Marty, F.M.; Bryar, J.M.; DeAngelo, D.J.; Baden, L.R. Invasive fungal disease in patients treated for newly diagnosed acute leukemia. Am J Hematol 2010, 85, 695-699, doi:10.1002/ajh.21776.

18. Neofytos, D.; Lu, K.; Hatfield-Seung, A.; Blackford, A.; Marr, K.A.; Treadway, S.; Ostrander, D.; Nussenblatt, V.; Karp, J. Epidemiology, outcomes, and risk factors of invasive fungal infections in adult patients with acute myelogenous leukemia after induction chemotherapy. Diagn Microbiol Infect Dis 2013, 75, 144-149, doi:10.1016/j.diagmicrobio.2012.10.001.

19. Caira, M.; Candoni, A.; Verga, L.; Busca, A.; Delia, M.; Nosari, A.; Caramatti, C.; Castagnola, C.; Cattaneo, C.; Fanci, R., et al. Pre-chemotherapy risk factors for invasive fungal diseases: prospective analysis of 1,192 patients with newly diagnosed acute myeloid leukemia (SEIFEM 2010-a multicenter study). Haematologica 2015, 100, 284-292, doi:10.3324/haematol.2014.113399.

20. Schnetzke, U.; Spies-Weisshart, B.; Yomade, O.; Fischer, M.; Rachow, T.; Schrenk, K.; Glaser, A.; von Lilienfeld-Toal, M.; Hochhaus, A.; Scholl, S. Polymorphisms of Toll-like receptors (TLR2 and TLR4) are associated with the risk of infectious complications in acute myeloid leukemia. Genes Immun 2015, 16, 83-88, doi:10.1038/gene.2014.67.

21. Fischer, M.; Spies-Weisshart, B.; Schrenk, K.; Gruhn, B.; Wittig, S.; Glaser, A.; Hochhaus, A.; Scholl, S.; Schnetzke, U. Polymorphisms of Dectin-1 and TLR2 Predispose to Invasive Fungal Disease in Patients with Acute Myeloid Leukemia. PLoS One 2016, 11, e0150632, doi:10.1371/journal.pone.0150632.

22. Cornely, O.A.; Maertens, J.; Winston, D.J.; Perfect, J.; Ullmann, A.J.; Walsh, T.J.; Helfgott, D.; Holowiecki, J.; Stockelberg, D.; Goh, Y.T., et al. Posaconazole vs. fluconazole or itraconazole prophylaxis in patients with neutropenia. N Engl J Med 2007, 356, 348-359, doi:10.1056/NEJMoa061094.

23. Ullmann, A.J.; Lipton, J.H.; Vesole, D.H.; Chandrasekar, P.; Langston, A.; Tarantolo, S.R.; Greinix, H.; Morais de Azevedo, W.; Reddy, V.; Boparai, N., et al. Posaconazole or fluconazole for prophylaxis in severe graft-versus-host disease. N Engl J Med 2007, 356, 335-347, doi:10.1056/NEJMoa061098.

24. Buckley, S.A.; Othus, M.; Vainstein, V.; Abkowitz, J.L.; Estey, E.H.; Walter, R.B. Prediction of adverse events during intensive induction chemotherapy for acute myeloid leukemia or highgrade myelodysplastic syndromes. Am J Hematol 2014, 89, 423-428, doi:10.1002/ajh.23661.

25. Kontoyiannis, D.P.; Selleslag, D.; Mullane, K.; Cornely, O.A.; Hope, W.; Lortholary, O.; CroosDabrera, R.; Lademacher, C.; Engelhardt, M.; Patterson, T.F. Impact of unresolved neutropenia in patients with neutropenia and invasive aspergillosis: a post hoc analysis of the SECURE trial. J Antimicrob Chemother 2018, 73, 757-763, doi:10.1093/jac/dkx423. 
26. Ray-Coquard, I.; Borg, C.; Bachelot, T.; Sebban, C.; Philip, I.; Clapisson, G.; Le Cesne, A.; Biron, P.; Chauvin, F.; Blay, J.Y. Baseline and early lymphopenia predict for the risk of febrile neutropenia after chemotherapy. Br J Cancer 2003, 88, 181-186, doi:10.1038/sj.bjc.6600724.

27. Yao, J.-F.; Li, N.; Jiang, J. Clinical Characteristics of Bloodstream Infections in Pediatric Acute Leukemia: A Single-center Experience with 231 Patients. Chin Med J (Engl) 2017, 130, 20762081, doi:10.4103/0366-6999.213411.

28. Kim, G.Y.G.; Burns, J.; Freyer, C.W.; Hamilton, K.W.; Frey, N.V.; Gill, S.I.; Hexner, E.O.; Luger, S.M.; Mangan, J.K.; Martin, M.E., et al. Risk of invasive fungal infections in patients with highrisk MDS and AML receiving hypomethylating agents. Am J Hematol 2020, 95, 792-798, doi:10.1002/ajh.25808.

29. Fianchi, L.; Leone, G.; Posteraro, B.; Sanguinetti, M.; Guidi, F.; Valentini, C.G.; Voso, M.T.; Pagano, L. Impaired bactericidal and fungicidal activities of neutrophils in patients with myelodysplastic syndrome. Leuk Res 2012, 36, 331-333, doi:10.1016/j.leukres.2011.11.012.

30. Schuster, M.; Moeller, M.; Bornemann, L.; Bessen, C.; Sobczak, C.; Schmitz, S.; Witjes, L.; Kruithoff, K.; Kohn, C.; Just, O., et al. Surveillance of Myelodysplastic Syndrome via Migration Analyses of Blood Neutrophils: A Potential Prognostic Tool. The Journal of Immunology 2018, 201, 3546-3557, doi:10.4049/jimmunol.1801071.

31. Dombret, H.; Seymour, J.F.; Butrym, A.; Wierzbowska, A.; Selleslag, D.; Jang, J.H.; Kumar, R.; Cavenagh, J.; Schuh, A.C.; Candoni, A., et al. International phase 3 study of azacitidine vs conventional care regimens in older patients with newly diagnosed $\mathrm{AML}$ with $>30 \%$ blasts. Blood 2015, 126, 291-299, doi:10.1182/blood-2015-01-621664.

32. Kantarjian, H.M.; Thomas, X.G.; Dmoszynska, A.; Wierzbowska, A.; Mazur, G.; Mayer, J.; Gau, J.P.; Chou, W.C.; Buckstein, R.; Cermak, J., et al. Multicenter, randomized, open-label, phase III trial of decitabine versus patient choice, with physician advice, of either supportive care or low-dose cytarabine for the treatment of older patients with newly diagnosed acute myeloid leukemia. J Clin Oncol 2012, 30, 2670-2677, doi:10.1200/jco.2011.38.9429.

33. Jalbut, M.M.; Brunner, A.M.; Amrein, P.C.; Ballen, K.K.; Hobbs, G.S.; Perry, A.M.; Joseph, C.P.; Fathi, A.T. Early infectious complications among patients treated with induction compared to hypomethylating therapy for acute myeloid leukemia. Leuk Lymphoma 2018, 59, 988-991, doi:10.1080/10428194.2017.1361028.

34. Kelly, C.M.; Shahrokni, A. Moving beyond Karnofsky and ECOG Performance Status Assessments with New Technologies. Journal of Oncology 2016, 2016, 6186543, doi:10.1155/2016/6186543.

35. Ostgård, L.S.; Kjeldsen, E.; Holm, M.S.; Brown Pde, N.; Pedersen, B.B.; Bendix, K.; Johansen, P.; Kristensen, J.S.; Nørgaard, J.M. Reasons for treating secondary AML as de novo AML. Eur J Haematol 2010, 85, 217-226, doi:10.1111/j.1600-0609.2010.01464.x.

36. Röllig, C.; Steffen, B.; Alakel, N.; Herbst, R.; Noppeney, R.; Hanoun, M.; Racil, Z.; SchäferEckart, K.; Krämer, A.; Neubauer, A., et al. Remission and Survival after Single Versus Double Induction with 7+3 for Newly Diagnosed Acute Myeloid Leukemia: Results from the Planned Interim Analysis of Randomized Controlled SAL-Daunodouble Trial. Blood 2020, 136, 1-3, doi:10.1182/blood-2020-140246.

37. Büchner, T.; Schlenk, R.F.; Schaich, M.; Döhner, K.; Krahl, R.; Krauter, J.; Heil, G.; Krug, U.; Sauerland, M.C.; Heinecke, A., et al. Acute Myeloid Leukemia (AML): different treatment strategies versus a common standard arm--combined prospective analysis by the German AML Intergroup. J Clin Oncol 2012, 30, 3604-3610, doi:10.1200/jco.2012.42.2907.

38. Kahl, C.; Krahl, R.; Becker, C.; Al-Ali, H.K.; Sayer, H.G.; Schulze, A.; Herold, M.; Hänel, M.; Scholl, S.; Hochhaus, A., et al. Long-term follow-up of the AML97 study for patients aged 60 years and above with acute myeloid leukaemia: a study of the East German Haematology and Oncology Study Group (OSHO). J Cancer Res Clin Oncol 2016, 142, 305-315, doi:10.1007/s00432-015-2045-8.

39. Brunkhorst, F.M.; Weigand, M.A.; Pletz, M.; Gastmeier, P.; Lemmen, S.W.; Meier-Hellmann, A.; Ragaller, M.; Weyland, A.; Marx, G.; Bucher, M., et al. [S3 Guideline Sepsis-prevention, 
diagnosis, therapy, and aftercare : Long version]. Med Klin Intensivmed Notfmed 2020, 115, 37-109, doi:10.1007/s00063-020-00685-0.

40. Brothman, A.R.; Persons, D.L.; Shaffer, L.G. Nomenclature evolution: Changes in the ISCN from the 2005 to the 2009 edition. Cytogenet Genome Res 2009, 127, 1-4, doi:10.1159/000279442.

41. International Standing Committee on Human Cytogenomic Nomenclature, M.-J.J.S.A.S.M. ISCN : an international system for human cytogenomic nomenclature (2016); 2016.

42. Thiede, C.; Koch, S.; Creutzig, E.; Steudel, C.; Illmer, T.; Schaich, M.; Ehninger, G. Prevalence and prognostic impact of NPM1 mutations in 1485 adult patients with acute myeloid leukemia (AML). Blood 2006, 107, 4011-4020, doi:10.1182/blood-2005-08-3167.

43. Stasik, S.; Eckardt, J.N.; Kramer, M.; Röllig, C.; Krämer, A.; Scholl, S.; Hochhaus, A.; Crysandt, M.; Brümmendorf, T.H.; Naumann, R., et al. Impact of PTPN11 mutations on clinical outcome analyzed in 1529 patients with acute myeloid leukemia. Blood Adv 2021, 5, 3279-3289, doi:10.1182/bloodadvances.2021004631.

44. Othus, M.; Kantarjian, H.; Petersdorf, S.; Ravandi, F.; Godwin, J.; Cortes, J.; Pierce, S.; Erba, H.; Faderl, S.; Appelbaum, F.R., et al. Declining rates of treatment-related mortality in patients with newly diagnosed AML given 'intense' induction regimens: a report from SWOG and MD Anderson. Leukemia 2014, 28, 289-292, doi:10.1038/leu.2013.176.

45. Stone, R.M.; Mandrekar, S.J.; Sanford, B.L.; Laumann, K.; Geyer, S.; Bloomfield, C.D.; Thiede, C.; Prior, T.W.; Dohner, K.; Marcucci, G., et al. Midostaurin plus Chemotherapy for Acute Myeloid Leukemia with a FLT3 Mutation. N Engl J Med 2017, 377, 454-464, doi:10.1056/NEJMoa1614359.

46. Castaigne, S.; Pautas, C.; Terré, C.; Raffoux, E.; Bordessoule, D.; Bastie, J.N.; Legrand, O.; Thomas, X.; Turlure, P.; Reman, O., et al. Effect of gemtuzumab ozogamicin on survival of adult patients with de-novo acute myeloid leukaemia (ALFA-0701): a randomised, open-label, phase 3 study. Lancet 2012, 379, 1508-1516, doi:10.1016/s0140-6736(12)60485-1.

47. Lancet, J.E.; Uy, G.L.; Cortes, J.E.; Newell, L.F.; Lin, T.L.; Ritchie, E.K.; Stuart, R.K.; Strickland, S.A.; Hogge, D.; Solomon, S.R., et al. CPX-351 (cytarabine and daunorubicin) Liposome for Injection Versus Conventional Cytarabine Plus Daunorubicin in Older Patients With Newly Diagnosed Secondary Acute Myeloid Leukemia. J Clin Oncol 2018, 36, 2684-2692, doi:10.1200/jco.2017.77.6112.

48. DiNardo, C.D.; Jonas, B.A.; Pullarkat, V.; Thirman, M.J.; Garcia, J.S.; Wei, A.H.; Konopleva, M.; Döhner, H.; Letai, A.; Fenaux, P., et al. Azacitidine and Venetoclax in Previously Untreated Acute Myeloid Leukemia. N Engl J Med 2020, 383, 617-629, doi:10.1056/NEJMoa2012971.

49. Fleischmann, M.; Scholl, S.; Frietsch, J.J.; Hilgendorf, I.; Schrenk, K.; Hammersen, J.; Prims, F.; Thiede, C.; Hochhaus, A.; Schnetzke, U. Clinical experience with venetoclax in patients with newly diagnosed, relapsed, or refractory acute myeloid leukemia. J Cancer Res Clin Oncol 2022, 10.1007/s00432-022-03930-5, doi:10.1007/s00432-022-03930-5.

50. Tey, A.; Shaw, B.; Cardamone, L.; Shepherd, S.; Paul, E.; Rogers, B.; Shortt, J. Risk factors for invasive fungal infection in 5-azacytidine treated patients with acute myeloid leukemia and myelodysplastic syndrome. Eur J Haematol 2021, 107, 181-189, doi:10.1111/ejh.13631.

51. Andréa, T.; Pierre, F.; François, D.; Catherine, C. Infections in myelodysplastic syndromes. Haematologica 2012, 97, 1459-1470, doi:10.3324/haematol.2012.063420.

52. Pagano, L.; Caira, M.; Candoni, A.; Offidani, M.; Martino, B.; Specchia, G.; Pastore, D.; Stanzani, M.; Cattaneo, C.; Fanci, R., et al. Invasive aspergillosis in patients with acute myeloid leukemia: a SEIFEM-2008 registry study. Haematologica 2010, 95, 644-650, doi:10.3324/haematol.2009.012054.

53. Hahn-Ast, C.; Glasmacher, A.; Mückter, S.; Schmitz, A.; Kraemer, A.; Marklein, G.; Brossart, P.; von Lilienfeld-Toal, M. Overall survival and fungal infection-related mortality in patients with invasive fungal infection and neutropenia after myelosuppressive chemotherapy in a tertiary care centre from 1995 to 2006. J Antimicrob Chemother 2010, 65, 761-768, doi:10.1093/jac/dkp507. 
54. Traber, K.E.; Symer, E.M.; Allen, E.; Kim, Y.; Hilliard, K.L.; Wasserman, G.A.; Stewart, C.L.; Jones, M.R.; Mizgerd, J.P.; Quinton, L.J. Myeloid-epithelial cross talk coordinates synthesis of the tissue-protective cytokine leukemia inhibitory factor during pneumonia. American Journal of Physiology-Lung Cellular and Molecular Physiology 2017, 313, L548-L558, doi:10.1152/ajplung.00482.2016.

55. Chang, H.; Kuo, M.C.; Lin, T.L.; Wu, J.H.; Wang, P.N. Pneumocystis jirovecii pneumonia in patients with acute myeloid leukaemia. Intern Med J 2018, 48, 81-83, doi:10.1111/imj.13668.

56. Wang, J.; Zhang, C.; Lin, J.; Zhang, L.; Li, J.; Yang, F. Clinical diagnostic value of spiral CT in invasive pulmonary fungal infection. Exp Ther Med 2019, 17, 4149-4153, doi:10.3892/etm.2019.7412.

57. Wasylyshyn, A.I.; Linder, K.A.; Kauffman, C.A.; Richards, B.J.; Maurer, S.M.; Sheffield, V.M.; Benitez Colon, L.; Miceli, M.H. Invasive Fungal Disease in Patients with Newly Diagnosed Acute Myeloid Leukemia. J Fungi (Basel) 2021, 7, doi:10.3390/jof7090761.

58. Gomes, M.Z.; Mulanovich, V.E.; Jiang, Y.; Lewis, R.E.; Kontoyiannis, D.P. Incidence density of invasive fungal infections during primary antifungal prophylaxis in newly diagnosed acute myeloid leukemia patients in a tertiary cancer center, 2009 to 2011. Antimicrob Agents Chemother 2014, 58, 865-873, doi:10.1128/aac.01525-13.

59. Aldoss, I.; Dadwal, S.; Zhang, J.; Tegtmeier, B.; Mei, M.; Arslan, S.; Al Malki, M.M.; Salhotra, A.; Ali, H.; Aribi, A., et al. Invasive fungal infections in acute myeloid leukemia treated with venetoclax and hypomethylating agents. Blood Advances 2019, 3, 4043-4049, doi:10.1182/bloodadvances.2019000930.

60. Ali, A.M.; Weisel, D.; Gao, F.; Uy, G.L.; Cashen, A.F.; Jacoby, M.A.; Wartman, L.D.; Ghobadi, A.; Pusic, I.; Romee, R., et al. Patterns of infectious complications in acute myeloid leukemia and myelodysplastic syndromes patients treated with 10-day decitabine regimen. Cancer Medicine 2017, 6, 2814-2821, doi:https://doi.org/10.1002/cam4.1231.

61. Hammond, D.; Sasaki, K.; Geppner, A.; Haddad, F.; Mohamed, S.; Rivera, D.; Siddiqui, M.; Alwash, Y.; Perez, J.R.; Morita, K., et al. Contemporary outcomes for adults with AML requiring ICU admission. Journal of Clinical Oncology 2021, 39, 7025-7025, doi:10.1200/JCO.2021.39.15_suppl.7025.

62. Mottal, N.; Issa, N.; Dumas, P.-Y.; Camou, F.; Sauvezie, M.; Gros, F.-X.; Cazaubiel, T.; Mourissoux, G.; Leroy, H.; Pigneux, A., et al. Reduce Mortality and Morbidity in Acute Myeloid Leukemia With Hyperleukocytosis With Early Admission in Intensive Care Unit: A Retrospective Analysis; 2020.

63. Krug, U.; Röllig, C.; Koschmieder, A.; Heinecke, A.; Sauerland, M.C.; Schaich, M.; Thiede, C.; Kramer, M.; Braess, J.; Spiekermann, K., et al. Complete remission and early death after intensive chemotherapy in patients aged 60 years or older with acute myeloid leukaemia: a web-based application for prediction of outcomes. The Lancet 2010, 376, 2000-2008, doi:https://doi.org/10.1016/S0140-6736(10)62105-8.

64. Quintás-Cardama, A.; Ravandi, F.; Liu-Dumlao, T.; Brandt, M.; Faderl, S.; Pierce, S.; Borthakur, G.; Garcia-Manero, G.; Cortes, J.; Kantarjian, H. Epigenetic therapy is associated with similar survival compared with intensive chemotherapy in older patients with newly diagnosed acute myeloid leukemia. Blood 2012, 120, 4840-4845, doi:10.1182/blood-2012-06-436055. 


\section{Compliance with Ethical Standards}

\section{Disclosure of potential conflicts of interest}

The authors have no relevant financial or non-financial interests to disclose. The authors have no conflicts of interest to declare that are relevant to the content of this article. The authors have no financial or proprietary interests in any material discussed in this article.

\section{Research involving human participants and/or animals}

The presented study does not include research involving animals or pharmacological research in human participants. The presented retrospective study was performed according to the Declaration of Helsinki.

\section{Informed consent}

All patients were included in the SAL registry (Study Alliance Leukemia). Patients gave their written informed consent for data acquisition and analysis after pseudonymization in the AML registry. The participation in this AML registry and the clinical analyses presented in this manuscript have been approved by the Ethical review committee of the University Hospital Jena. 


\section{Figures}

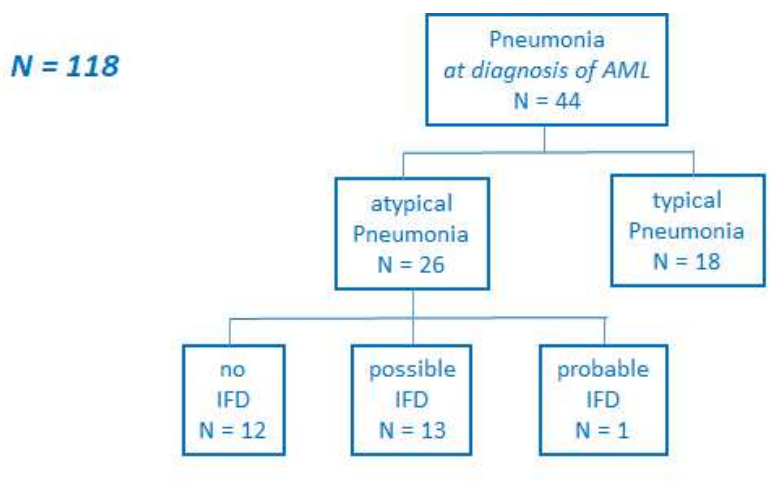

palliative AML treatment

$N=108$

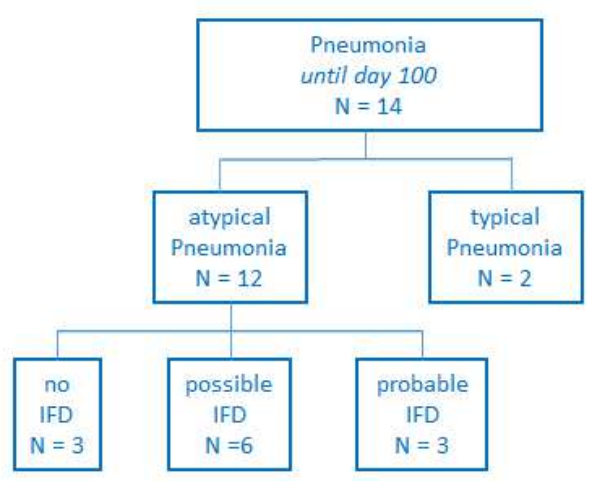

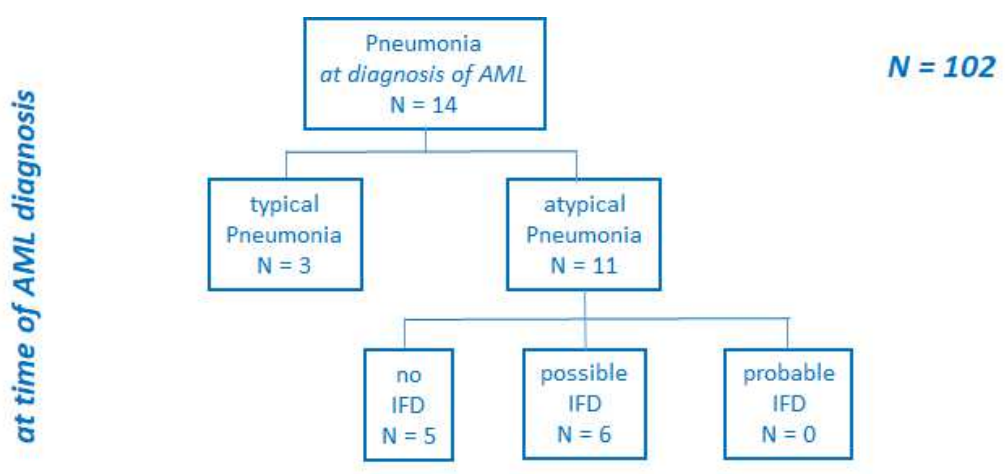

AML induction chemotherapy

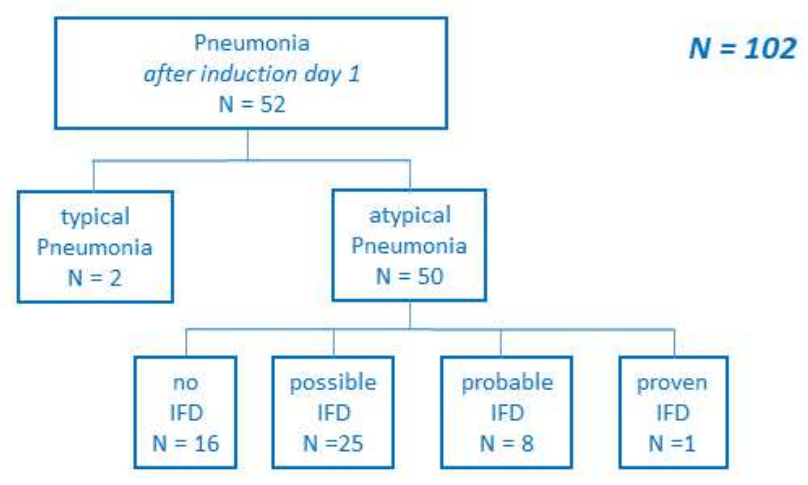

\section{Figure 1}

CONSORT diagram of time-dependent pneumonia subtypes for both patient groups. Distribution of absolute numbers of patients presenting with pneumonia either at the time of AML diagnosis (upper part) or after initiation of AML therapy (lower part) for patients allocated to palliative AML treatment (left) or induction chemotherapy (right). 

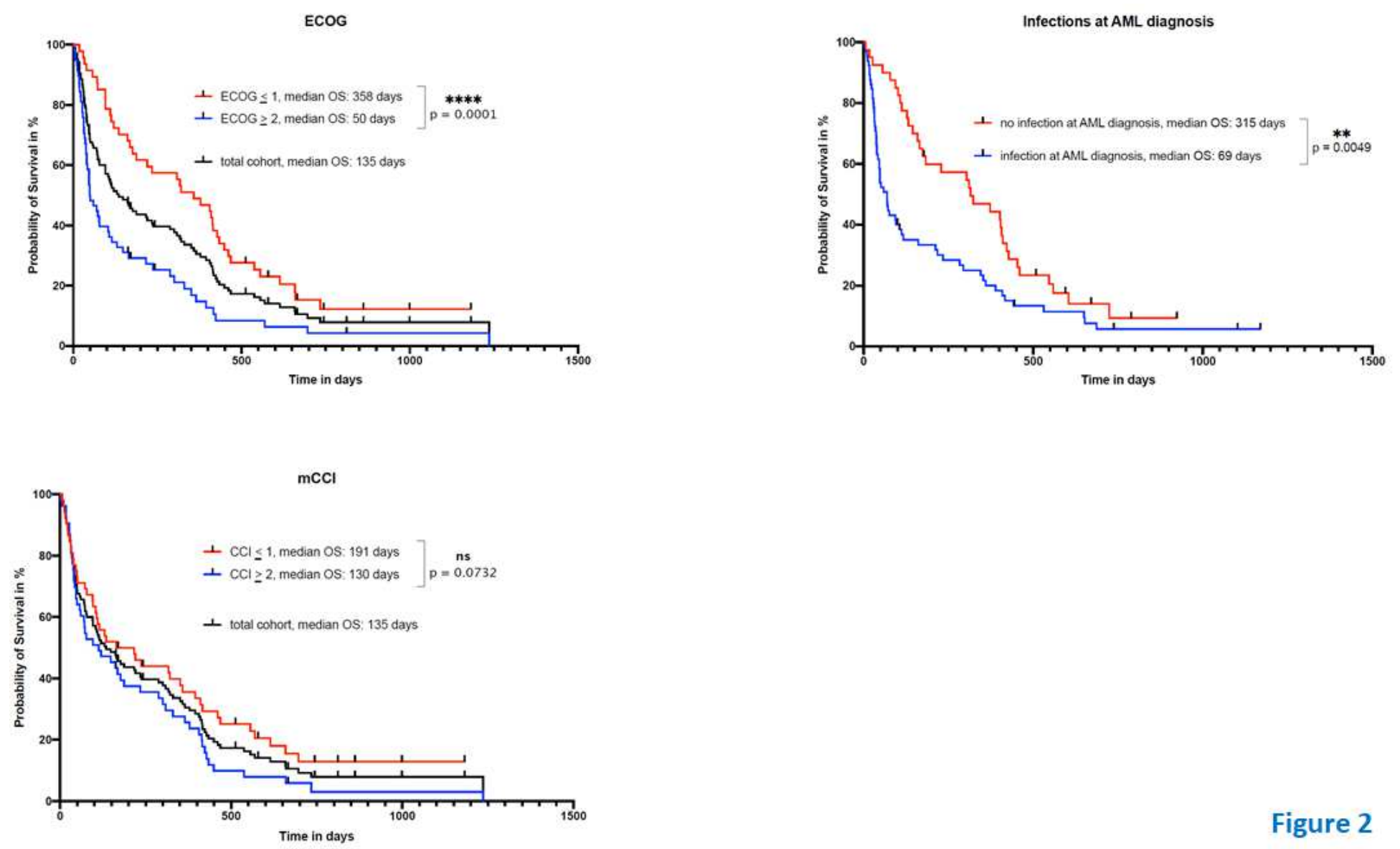

Figure 2

Figure 2

Kaplan-Meier estimates for overall survival (OS) dependent on the ECOG performance score (A) or on the modified Charlson comorbidity index (B) for AML patients undergoing palliative treatment.

\section{Supplementary Files}

This is a list of supplementary files associated with this preprint. Click to download.

- 20220220SupplementFigureS1.pptx

- 20220220SupplementFigureS2.pptx

- 20220220SupplementFigureS3.pptx 